\title{
Factors which influence concordance among measurements obtained by different pulse oximeters currently used in some clinical situations
}

\author{
Candelaria de la Merced Díaz-González PhD, Nurse ${ }^{1}$ (D) | Milagros de la Rosa-Hormiga PhD, \\ Professor $^{2}$ | Josefa M. Ramal-López PhD, Professor ${ }^{2}$ | Juan José González-Henríquez PhD, \\ Professor $^{2}$ | María Sandra Marrero-Morales PhD, Professor ${ }^{2}$
}

${ }^{1}$ Hospital Universitario Insular de Gran Canaria, Las Palmas, Islas Canarias, Spain

${ }^{2}$ Facultad de Ciencias de la Salud, Universidad de Las Palmas de Gran Canaria (ULPGC), Islas Canarias, Spain

Correspondence

Candelaria de la Merced Díaz-González, Hospital Insular de Gran Canaria, Unidad de Hospitalización de Traumatología (planta $9^{\circ}$ sur), Avenida Marítima del Sur $\mathrm{s} / \mathrm{n}$, Las Palmas de Gran Canaria (35016), Islas Canarias, Spain.

Email: cmdiazglez@yahoo.es

Funding information

This project is financed by the Fundación Canaria de Investigación Sanitaria FUNCANIS (Canarian Foundation of Health Research), application for nursing research grants 2014, in cooperation with Colegios Oficiales de Enfermería de Las Palmas and Santa Cruz de Tenerife (Official Colleges of Nursing in Las Palmas and Santa Cruz de Tenerife).
Aims and objectives: To evaluate both concordance among those measurements obtained by three different pulse oximeters currently used by nursing professionals in hospital units and the factors which can influence this concordance.

Background: Many models of wireless pulse oximeters in the present market do not offer possibility of calibration and, therefore, they do not ensure patients' safety in daily clinical practice.

Design: This is a descriptive and cross-sectional study. The sample of patients (140) was selected from such hospital units, and all of them had to fulfil inclusion and exclusion criteria for participation.

Methods: The instruments used to carry out this research were a monitor (calibrated), two models of portable wireless pulse oximeters (used for 3 years by the nursing staff, without being calibrated), a tympanic thermometer and a weather meter. The concordance correlation coefficient (CCC) was used to establish the concordance, whereas the Landis-Koch criteria were used to interpret the results.

Results: The concordance among the three devices was considered as "good" (CCC: 0.925 and $0.974(95 \%))$. The CCC (0.925) for saturation measures was regarded as "very good"/"almost perfect," and the pulse measure was considered as "very good" CCC 0.974, providing in both cases a high level of concordance (CCC > 0.91).

Conclusions: The overall concordance as regards pulse and oxygen saturation among the three pulse oximeters analysed is considered as "very good" according to the Landis-Koch criteria.

Relevance to clinical practice: There exists a "very good" concordance among two wireless oximeters which have been used by the health staff for 3 years and which did not offer any possibility of calibration and one monitor which belongs to the healthcare institution. This aspect is of crucial importance in daily clinical practice, and it is also relevant to ensure patient's safety.

KEYWORDS

gases, monitoring, pulse oximetry, safety, transcutaneous 


\section{1 | INTRODUCTION}

Over the past few years, most manufacturers and models of wireless pulse oximeters in the present market lead us to consider the reliability and accuracy of these devices in daily clinical practice.

Peripheral pulse oximetry, performed on a daily basis by the health professionals in the hospital environment, aims at detecting and registering possible oxygen deficiency in blood. The reading of these recordings by the health professional leads us to a diagnostic suspicion and is associated to a specific therapeutic attitude which could be inaccurate if the reading of the device is not the correct one. Therefore, it is of crucial importance to know whether the different instruments which are presently used to measure oxygen saturation in our hospital unit show concordance among measurements.

\subsection{Aim}

To know the clinical and environmental factors which can modify the concordance among those measurements obtained by three different pulse oximeters currently used by health professionals in different clinical and environmental situations.

1. To evaluate the concordance among measurements obtained by three different pulse oximeters currently used by nursing professionals in the hospital units.

2. To identify the clinical and environmental factors which can influence those measurements obtained by the three pulse oximeters.

\section{2 | Background}

Pulse oximetry is a technique used to measure oxygen level in haemoglobin in blood vessels. It measures oxygen saturation percentage. At present, it can be considered as the "fifth vital sign" (Sola, Chow, $\&$ Rogido, 2005). To determine blood oxygen percentage in a peripheral and noninvasive way, instruments such as pulse oximeters, oximeters or saturometers can be used. These devices let us measure blood oxygen percentage.

Nevertheless, there are other factors associated to individuals, to observers and to measuring devices (Bohnhorst, Peter, \& Owitz, 2000; Kawagishi, Kanaya, Nakawama, Kurosawa, \& Namiki, 2004), that can affect measurements (Argimon Pallán \& Jiménez Villa, 2004; Hernández Aguado, Porta Serra, Miralles, García Benavides, \& Bolúmar, 1990).

Some factors (Lisa Catón, 2003) appear to influence oxygen saturation measurement such as severe anaemia, patient's movements, intense light, peripheral vascular problems, venous pulse and interferences with other devices.

A previous research (Díaz-González, De la Rosa Hormiga, Ramal López, Déniz Rivero, \& Marrero Morales, 2014) carried out by the authors of this paper has proven that there is a "good" concordance among those wireless pulse oximeters used by the health staff, which did not offer any possibility of calibration, and one which

\section{What is already known about this topic?}

- Peripheral pulse oximetry is performed on a daily basis by health professionals in the hospital environment with devices which, sometimes, offer no possibility of calibration.

- Factors such as severe anaemia, patient's movements, intense light, vascular problems, venous pulse and interferences with other devices can influence oxygen saturation measurement.

- There is a high concordance among three oximeters: two "new" wireless oximeters and a hospital monitor calibrated by the electromedicine service.

\section{What this paper adds}

- There exists a "very good" concordance among two wireless oximeters which have been used by the health staff for three years and which did not offer any possibility of calibration and one monitor which belongs to the healthcare institution. This aspect is of crucial importance in daily clinical practice, and it is also relevant to ensure patient's safety.

- Age, patient's temperature, haemoglobin, and room temperature and humidity are closely related to those saturation and/or pulse measurements performed both by the two wireless oximeters and by the monitor.

belonged to the healthcare institution, which was regularly examined and calibrated in controlled conditions. The aim of this research was both to replicate the previous study including new clinical and environmental variables and to identify the way in which these devices operate depending on new possible environmental variables and the effect of the time factor ( 3 years of use) of each device without being calibrated.

\section{2 | METHODS}

\section{1 | Study design}

This is a descriptive and cross-sectional study, which was performed in the Hospital Unit of Trauma and Orthopaedic Surgery (HUTOS) in Hospital Universitario Insular de Gran Canaria (HUIGC) in 2015.

\subsection{Setting and sample}

The sample of patients was selected from such hospital unit in the fourth quarter in 2015.

Exclusion criteria for participation in this study were the following ones: patients who presented fractures or amputation of their fingers and arms and those patients suffering from any type of social isolation and cognitive impairment. 
A template was designed to collect data. It was divided into two sections: the first one includes those data related to sociodemographic aspects and independent variables (age, sex, previous pathologies)*, and the second section incorporates the measurements obtained by the three pulse oximeters currently used in this hospital.

\section{3 | Ethical consideration}

This research has been authorised by the Continuing Education Committee, Education and Research of the management of the HUIGC with authorisation date 25 November 2013 (record number 04/13).

\section{4 | Measurements/Instruments}

The instruments used were a Nelcor ${ }^{\circledR} 5600$ monitor (Tyco Healthcare 2006) to measure fixed peripheral oximetry, owned by the institution (calibrated by the electromedicine service every year), two models of portable wireless pulse oximeters Contec ${ }^{\circledR}$ (CMS-50A and CMS-50D models) (Contecmed: Pulse oximeter Series, 2017), also owned by the institution, which have been used for 3 years by the nursing staff, without being calibrated. Moreover, these two models have been already used in previous studies.

\subsection{1 | Instruments}

Nelcor $^{\circledR} 5600$ monitor (LED display), red light of wavelength $660 \mathrm{~nm}$ and an infrared light of wavelength 940 . This instrument can measure oxygen saturation, cardiac frequency, electrocardiogram, breathing rate, temperature, plethysmographic curve, measuring range SPO2 1\%-100\%, precision \%SPO2 \pm 1 SD\%; portable wireless pulse oximeter Contec ${ }^{\circledR}$ CMS-50A (grey colour, LED display, red light of wavelength $660 \mathrm{~nm}$ and an infrared light of wavelength $880 \mathrm{~nm}$ ). This device can measure oxygen saturation, cardiac frequency and plethysmographic curve, measuring range SPO2 0\%-100\%, precision SPO2 70\%-100\%); portable wireless pulse oximeter Contec ${ }^{\circledR}$ CMS-50D (LED display. It can measure oxygen saturation and cardiac frequency SPO2 35\%-100\%, precision SPO2 70\%-100\%). This monitor has been calibrated by the electromedicine service. Both portable wireless pulse oximeters were acquired 3 years ago, and they have not been calibrated. The Tympanic thermometer Genius ${ }^{\circledR} 2$ (Medtronic/Covidien, 2016) (temperature range $33^{\circ} \mathrm{C}$ a $42^{\circ} \mathrm{C}$, as regards resolution and precision), owned by the institution, is currently used and calibrated by the electromedicine service. Kestrel ${ }^{\circledR} \mathrm{K} 4000$ weather meter (Nielsen-Kellerman, 2016) (temperature range $-45^{\circ} \mathrm{C}$ a $125^{\circ} \mathrm{C}$, resolution $0.1^{\circ} \mathrm{C}$ and precision $\pm 0.5^{\circ} \mathrm{C}$ (between-29 $9^{\circ}$ and $-70^{\circ}$ ); humidity range $5 \%-95 \%$, resolution $0.1 \%$ and precision $\pm 3 \%$ ) has been acquired and calibrated for the present study.

\subsection{Data collection/Procedure}

Measurements using the three different pulse oximeters were always performed by the same nurse. Moreover, pulse oximeters were always placed on the same finger of the patient, measuring saturation after 30 seconds (s) with the measuring device placed on the fingertip, being the process repeated three times with the three saturometers. Other measurements performed were the patient's temperature in degrees Celsius $\left({ }^{\circ} \mathrm{C}\right)$, arterial blood measured in millimetres of mercury $(\mathrm{mm} \mathrm{Hg}$ ), on the same finger where the pulse oximetry measurement was performed, room temperature $\left({ }^{\circ} \mathrm{C}\right)$ and humidity (\%), identifying the presence of natural or artificial light.

\section{6 | Data analysis}

The descriptive statistics used were mean, standard deviation (SD), range and the overall concordance correlation coefficient (CCC) (Barnhart, Haber, \& Song, 2002; Barnhart, Song, \& Haber, 2005; Carrasco \& Martinez, 2015; Lin, 1989). Correlations among independent variables and those measurements performed with the three pulse oximeters were explored using Pearson's correlation coefficient, whereas categorical variables (sex and hand) were recoded numerically (male $1 /$ female 2 ) to carry out the $t$ test of independent samples among groups for each categorical variable. The overall CCC has been calculated using the variance components from a linear mixed model with multiple measurements by subject and instrument (Carrasco \& Martinez, 2015). The detection of possible systematic errors was explored by means of Bland and Altman (1986) diagrams for saturation and pulse, and the results were interpreted using the Landis and Koch (1977) criteria: CCC $\geq 0.91$ indicates a very good concordance, [0.71-0.90] good concordance, [0.51-0.70] moderate concordance, [0.31-0.50] poor concordance, $<0.31$ bad concordance.

All statistical analyses were performed using the statistical package IBM SPSS 19.0 (IBM Corp. Released, 2010), the R Project for Statistical Computing (R Core Team, 2016) and R package "cccrm" (Carrasco \& Martinez, 2015).

\section{RESULTS}

One hundred and forty patients were selected, 72 male patients (51.4\%) and 68 female patients (48.6\%) with a mean age of 59.3, a SD of 14.9 and a range of 26-88 years old. Patients (100\%) did not require oxygen therapy during measurement. About 72 (51.4\%) measurements were performed in fingers of their right hand, whereas 68 $(48.6 \%)$ in fingers of their left hand. The mean temperature of patients was $36.2^{\circ} \mathrm{C}$ with SD 0.51 (Table 1).

TABLE 1 Descriptive statistics

\begin{tabular}{llllll} 
Descriptive Statistics & & & & & \\
\hline & N & Min & Max & Mean & \multicolumn{1}{l}{ SD } \\
Age & 140 & 26.0 & 88.0 & 59.37 & 14.91 \\
Patient temperature & 140 & 35.0 & 37.3 & 36.28 & 0.51 \\
\hline Room temperature & 140 & 23.0 & 26.1 & 24.51 & 0.49 \\
Room humidity \% & 140 & 46.0 & 54.0 & 50.85 & 1.95 \\
\hline Haemoglobin gr/dl & 116 & 7.5 & 15.5 & 11.71 & 2.37 \\
\hline
\end{tabular}


TABLE 2 Descriptive statistics

\begin{tabular}{|lllllr}
\hline Descriptive statistics & \multicolumn{1}{c}{ N } & Min & Max & Mean & \multicolumn{1}{c}{ SD } \\
\hline Mean Saturation _monitor & 140 & 91.5 & 100.0 & 96.17 & 2.30 \\
\hline Mean Pulse _Monitor & 140 & 53.0 & 113.0 & 81.08 & 13.67 \\
\hline Mean Saturation_CMS50A & 140 & 91.0 & 99.0 & 95.86 & 2.22 \\
\hline Mean Pulse_CMS50A & 140 & 53.0 & 111.0 & 80.51 & 13.59 \\
\hline Mean Saturation_CMS50D & 140 & 90.5 & 98.5 & 95.96 & 1.97 \\
\hline Mean Pulse_CMS50D & 140 & 54.0 & 112.0 & 80.97 & 13.68
\end{tabular}

The independent variables related to the patients' room were the following ones: room temperature was $24.5^{\circ} \mathrm{C}$ with $S D 0.49$ and a range of $\left[23-26.1^{\circ} \mathrm{C}\right]$. As regards humidity, the mean was $50.8 \%$ with SD 1.95 and a range of [46\%-54\%] (Table 1).

The concomitance of pathologies, which could influence blood oxygen measurement, was identified in the sample, and it was found that 48 patients (34.3\%) suffered from hypertension, 28 (20\%) from diabetes mellitus, 44 (31.4\%) from cardiovascular disorders, 24 (17.1\%) from respiratory disorders and 16 (11.4\%) presented toxic habits (smoking, drinking or drug consumption).

Table 2 shows the descriptive statistics obtained by the three pulse oximeters both for saturation and for pulse. The overall concordance among the three devices (Table 3) was considered as "good," with a concordance correlation coefficient of 0.925 for oxygen saturation and 0.974 for pulse.

With the aim of verifying the possible presence of systematic, constant and proportional errors, a graphic study was carried out using Bland-Altman diagrams (Figures 1-3) where there is a clear evidence of the absence of systematic errors. To understand the diagrams, we must take into account that the central horizontal line represents the mean difference (bias in estimation) and the upper and lower lines represent two SD (random fluctuations) (Figures 4 6). Thus, if there is a concordance, the values are expected to be around the mean and within the two SD of the mean. The limits have been calculated taking into account the $95 \%$ for each comparison (mean difference $\pm 1,96 S D$ of the difference), indicating the distance between the measurements performed by two oximeters. If the differences within the mean $S D \pm 1,96$ are not clinically important, the two oximeters can be used interchangeably.

High CCC among the three instruments, both as regards saturation and heart rate, indicate that the three measurements are interchangeably, proving, in this sense, the validity of the two

TABLE 3 Concordance correlation coefficient (saturation and pulse)

\begin{tabular}{llll}
\multicolumn{4}{l}{ Concordance Correlation Coefficient (CCC) } \\
\hline & & \multicolumn{2}{l}{$\mathbf{9 5 \% \text { Confidence Interval }}$} \\
\cline { 3 - 4 } & CCC & Lower Bound & Upper Bound \\
Saturation & 0.925 & 0.893 & 0.945 \\
Pulse & 0.974 & 0.963 & 0.979
\end{tabular}
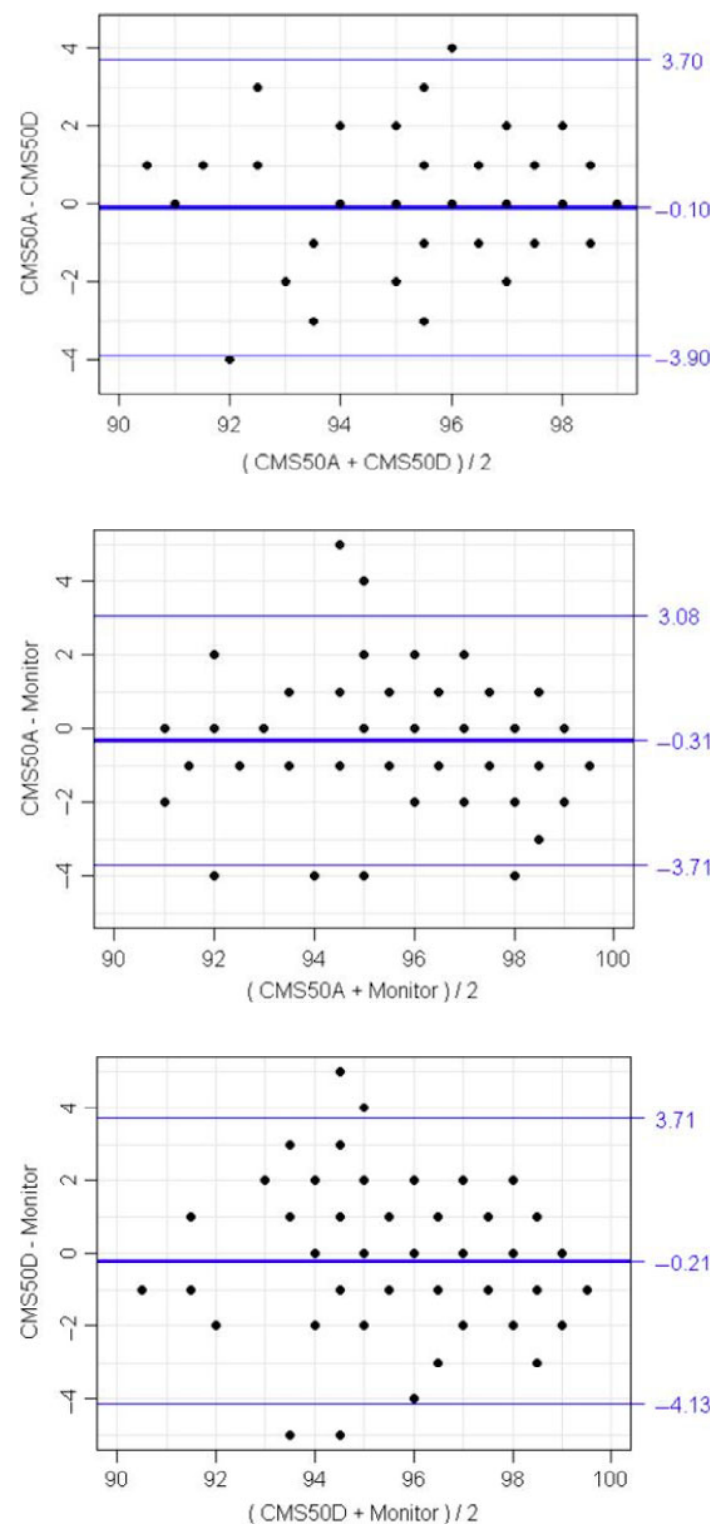

FIGURE 1 - 3 Bland-Altman diagram for saturation among monitor and wireless oximeters. Line --- represents the mean and line ---upper and lower $\pm 2 S D$. Thus, in Figure 1, only two of the 32 values (scores) are beyond the limits of the agreement, being the rest of values within those limits [Colour figure can be viewed at wileyonlinelibrary.com]

instruments which are not calibrated as opposed to the instrument calibrated by the institution.

According to Landis-Koch criteria (Landis \& Koch, 1977), the CCC (0.925) was "very good"/"almost perfect" as regards measure for saturation, whereas the measure for pulse was considered as "very good" (CCC 0.974), showing in both cases a high degree of concordance (CCC $\geq 0.91$ ) (Prieto, Lamarca, \& Casado,1998).

As regards correlations (Table 4 ), saturation implies a negative association with humidity $(r=-0.321)$. Pulse is directly related to the patients' temperature $(r=0.341)$ and the room temperature $(r=0.187)$, whereas the correlation is inverse as regards the amount of haemoglobin in the patient $(r=-0.222)$. According to the rules of thumb suggested by Hinkle, Wiersma \& Jurs (Hinkle, Wiersma, \& 

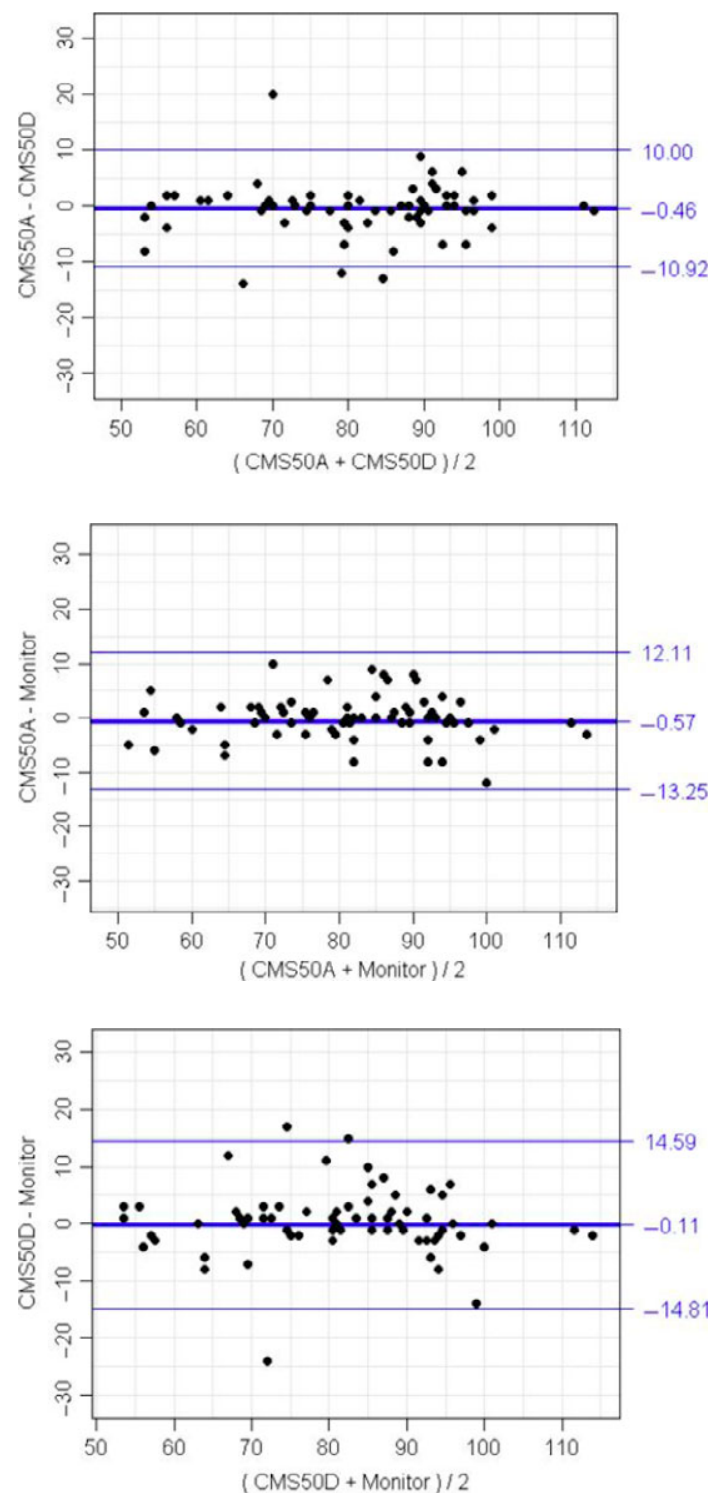

FIGURE 4-6 Bland-Altman diagram for pulse among monitor and wireless oximeters[Colour figure can be viewed at wileyonlinelibrary.com]

Jurs, 1997), the strength of the relationship between saturation and humidity, and pulse and patients' temperature are low. Approximately 11 per cent of the variance of pulse and saturation is associated with the variance of patients' temperature and humidity, respectively. All other correlations were negligible or little if any correlation. On the other hand (Table 5), there were no sex differences as regards pulse and saturation. Nevertheless, the mean difference between left and right hand pulse is significantly distinct. This difference disappears after adjustment for patients' temperature and age. Moreover, the mean difference as regards saturation between the right and left hand is remarkable, although this disappears after adjustment for age and sex.

If we compare the results obtained in the present study (saturation variable) to those obtained in the previous research (DíazGonzález et al., 2014), where ICC was 0.882 in opposition to CCC 0.925 (Cheng Chen \& Huiman X. Barnhart (Chen \& Barnhart, 2008) proved that both coefficients are approximately equal), we can state that further comparisons have not been possible since present variables were not included in the previous study. Contrary to the hypothesis stated in this research, concordance among the measurements obtained by the three pulse oximeters has increased after 3 years in use without being calibrated.

\section{DISCUSSION}

Following the recommendations given by other authors (Lisa Catón, 2003), different variables have been introduced in the present study: amount of haemoglobin, patient's temperature and environmental humidity and temperature. These variables have been introduced with the aim of identifying factors that could influence the reading of the pulse oximeters, providing confirmation of the relation in the different levels of meaning among all the variables with the measurements obtained.

Despite the recommendations given by electromedicine (Lisa Catón, 2003) about the importance of sensors in these type of devices, their calibration and measurements accuracy - after identifying many mistakes which have been made due to the different wavelengths in LED and the risks which these mistakes can produce in patients, especially in conditions with low levels of oxygen saturation in arterial blood - the mistakes mentioned above have not been identified in the present study, although both wireless oximeters have not been calibrated in the last 3 years.

TABLE 4 Correlations

\begin{tabular}{|c|c|c|c|c|c|c|}
\hline & & Age & $\begin{array}{l}\text { Room } \\
\text { Humidity \% }\end{array}$ & $\begin{array}{l}\text { Room Temperature } \\
\text { (Degrees Celsius) }\end{array}$ & $\begin{array}{l}\text { Haemoglobin } \\
\mathrm{Gr} / \mathrm{dl}\end{array}$ & $\begin{array}{l}\text { Patient Temperature } \\
\text { (Degrees Celsius) }\end{array}$ \\
\hline \multirow[t]{3}{*}{ Mean Saturation_Monitor } & Pearson Correlation & -0.166 & $-0.321^{* *}$ & -0.147 & -0.014 & -0.155 \\
\hline & Sig. (2-tailed) & 0.051 & 0.000 & 0.084 & 0.880 & 0.066 \\
\hline & $N$ & 140 & 140 & 140 & 140 & 140 \\
\hline Mean Pulse_Monitor & Pearson Correlation & 0.152 & 0.096 & $0.187^{*}$ & $-0.222^{*}$ & $0.341^{* *}$ \\
\hline
\end{tabular}

${ }^{*}$ Correlation is significant at the 0.05 level (2-tailed).

${ }^{* *}$ Correlation is significant at the 0.01 level (2-tailed). 


\begin{tabular}{|c|c|c|c|c|c|c|}
\hline & \multicolumn{3}{|l|}{ Hand } & \multicolumn{3}{|l|}{ Sex } \\
\hline & Left hand & Right hand & 95\% C.I. & Male & Female & 95\% C.I. \\
\hline Mean Saturation_Monitor & 95.73 & 96.58 & $(-1.6 ;-0.08)$ & 96.19 & 96.14 & $(-0.7 ; 0.8)$ \\
\hline Mean Pulse_Monitor & 85.01 & 77.3 & $(3.9 ; 12.2)$ & 79.13 & 83.14 & $(-8.5 ; 0.5)$ \\
\hline
\end{tabular}

TABLE 5 t test of independent variables among groups in each categorical variable
In the sample studied, no cases of oxygen intoxication or laryngitis were found. In this sense, the loss of utility of pulse oximetry, which is associated to these cases, as stated by some authors (Rodríguez, Garrido, Martínez, \& García, 2013), cannot be proven.

The portable haemoglobinometer (Rojas-Pérez, 2006) is a measuring device which is being increasingly incorporated in wireless oximeters and can be a new device to be introduced in this type of study, where a single instrument can measure different parameters, although the possibility of its calibration is currently unknown. On the other hand, the introduction of this new technology can imply a high demand in healthcare settings (overall in hospital and emergency services) due to their low cost if it is compared to the cost of maintenance of a standard device in the above-mentioned services and the cost which is added of the finger sensor used individually. These sensors must be changed frequently with each patient if we want to get a proper functioning. Furthermore, there is also a need of change when the monitor is being shared by other patient. The analytical controls of haemoglobin figures must also be considered. All these aspects imply a progressive increase in cost for the health institution.

The introduction of new functions in pulse oximeters implies progress as regards its ease of use. Nevertheless, it leads us to analyse if the increase in measuring parameters in a physical device which has not been inspected and calibrated, will continue being safe showing those measurements and records performed by health professionals with reliability, and if they are, consequently, efficient to perform a right diagnostic and medical treatment in the different clinical situations in which they are going to be used.

Another aspect to bear in mind is related to the safety guarantee of those data provided by the different pulse oximeters. This aspect has to do with the right interpretation of the results as regards those measurements obtained. This interpretation does not only depend on the device reliability, but also on the training of those who use it. In this sense, a recently published study (Reséndiz, Gómez, \& Orea, 2004) shows that $80 \%$ of those people who use these devices are able to interpret what the oximeter measures, $40 \%-45 \%$ know how they function and only $10 \%-15 \%$ are able to interpret the haemoglobin dissociation curve. This fact makes us think that it is necessary to open new lines of research which let us identify the level of knowledge and training of health professionals when using these measuring devices and, of course, future devices which appear on the market thanks to technological advances.

To sum up, it is extremely important to guarantee the efficacy and reliability of those measuring devices which are being daily used in investigation and clinical practice and to enhance the need for continuous professional development of those who use these measuring devices to make clinical decisions with the aim of satisfying key aspects related to patient's safety.

Although the present study shows a "very good" concordance among the three pulse oximeters, it is convenient and recommendable to inspect and calibrate all those devices which are being used in the clinical setting according to the indications of each model and brand. In this sense, this can facilitate an optimal planning of the interventions carried out by the health professionals involved. However, we must consider that the total sample ( $n=140$ ) had not been prescribed oxygen therapy. Therefore, we do not know how to modify the concordance among individuals with this treatment and those who did not receive it, what could imply a future line of research.

Due to the existence of previous studies (Salas \& Suárez, 2012) in scenarios where oximetry loses its utility and where there is a great variety of situations and artefacts which can affect the correct reading of the oximeter, this investigation group is presently researching in this field of study.

\section{5 | CONCLUSION}

The overall concordance as regards pulse and oxygen saturation among the three pulse oximeters analysed is considered as "very good" in both cases according to the Landis-Koch criteria (1977). These results lead us to conclude that in daily clinical practice, health professionals (doctors and nurses) in hospital services, where these devices are being used, can confirm the reliability of the use of both wireless pulse oximeters, which have not been calibrated for three years, as regards their results, taking into account the limitations of the present study due to the absence of "gold standard", arterial gasometry.

\section{RELEVANCE TO CLINICAL PRACTICE}

There exists a "very good" concordance among two wireless oximeters which have been used by the health staff for 3 years and which did not offer any possibility of calibration and one monitor which belongs to the healthcare institution. This aspect is of crucial importance in daily clinical practice and it is also relevant to ensure patient's safety.

Quantitative variables such as room humidity and patient's temperature are related to the measurement of saturation and pulse, respectively. In both cases, the strength of the relationship is low. 


\section{CONFLICTS OF INTEREST}

The authors declare no potential conflicts of interest with respect to the research, authorship and/or publication of this article.

\section{CONTRIBUTIONS}

CMDG performed data collection. MRH, JMRL, JJGH and MSMM participated in study design, analysis and manuscript preparation.

\section{ORCID}

Candelaria de la Merced Díaz-González iD http://orcid.org/00000003-1797-4752

\section{REFERENCES}

Argimon Pallán, J. M., \& Jiménez Villa, J. (2004). Métodos de investigación clínica y epidemiológica. Madrid, https://doi.org/10.1016/ b978-84-8174-709-6.50011-7

Barnhart, H. X., Haber, M., \& Song, J. (2002). Overall concordance correlation coefficient for evaluating agreement among multiple observers. Biometrics, 58(4), 1020-1027.

Barnhart, H. X., Song, J., \& Haber, M. J. (2005). Assessing intra, inter and total agreement with replicated readings. Statistics in Medicine, 24(9), 1371-1384. https://doi.org/10.1002/sim.2006

Bland, J. M., \& Altman, D. G. (1986). Statistical methods for assessing agreement between two methods of clinical measurement. Lancet, 1 , 307-310. https://doi.org/10.1016/s0140-6736(86)90837-8

Bohnhorst, B., Peter, C. S., \& Owitz, C. F. (2000). Pulse oximeters' reliability in detecting hypoxemia and bradycardia; comparison between a conventional and two new generations of oximeters. Critical Care Medical, 28, 165-168. https://doi.org/10.1097/00003246-200005 000-00050

Carrasco, J. L., \& Martinez, J. P.. (2015). Cccrm: Concordance correlation coefficient for repeated (and non-repeated) measures. Retrieved from https://CRAN.R-project.org/package=cccrm

Chen, C., \& Barnhart, H. X. (2008). Comparison of ICC and CCC for assessing agreement for data without and with replications. Computational Statistics \& Data Analysis, 53(2), 554-564.

Contecmed: Pulse oximeter Series (2017). [Internet]. Qinhuangdao: Contec Medical Systems Co., Ltd. Available at: http://www.contecmed. com/index.php?option=com_virtuemart\&ltemid=592 (accessed 29 August 2017).

Díaz-González, C. M., De la Rosa Hormiga, M., Ramal López, J. M., Déniz Rivero, Y., \& Marrero Morales, M. S.. (2014). Concordance among measurements obtained by three pulse oximeters currently used by health professionals. Journal of Clinical and Diagnostic Research 8 (8), MC09-MC12. https://doi.org/10.7860/jcdr/2014/8874.4763

Hernández Aguado, I., Porta Serra, M., Miralles, M., García Benavides, F., \& Bolúmar, F. (1990). La cuantificación de la variabilidad en las observaciones clínicas. Medicina Clínica, 95, 424429

Hinkle, D. E., Wiersma, W., \& Jurs, S. (1997). Applied statistics for the behavioral sciences. Boston, MA: Houghton Mifflin.
IBM Corp. Released (2010). IBM SPSS Statistics for Windows, Version 19.0. Armonk, NY: IBM Corp.

Kawagishi, T., Kanaya, N., Nakawama, M., Kurosawa, S., \& Namiki, A. (2004). A comparison of the failure times of pulse oximeters during blood pressure cuff-induced hypo perfusion in volunteers. Anesthesia \& Analgesia, 99(3), 793-796. https://doi.org/10.1213/01.ane.0000130343.66453.37

Landis, J. R., \& Koch, G. G. (1977). The measurement of observer agreement for categorical data. Biometrics, 33, 159-174. https://doi.org/ $10.2307 / 2529310$

Lin, L. I.-K.. (1989). A concordance correlation coefficient to evaluate reproducibility. Biometrics, 45(1), 255-268. Retrieved from http:// www.jstor.org/stable/2532051

Lisa Catón, V. (2003). La Pulsioximetría. Formación Médica Continuada en Atención Primaria, 10(6), 399-400. https://doi.org/10.1016/s11342072(03)75927-1

Medtronic/Covidien. (2016): Genius 2 Tympanic Thermometer[Internet]. Dublin: Covidien. http://www.medtronic.com/covidien/products/ther mometry/genius-2-tympanic-thermometer. (accessed 15 January 2016).

Nielsen-Kellerman (2016): Kestrel 4000 Weather \& Environmental Meter in Orange [Internet]. Pennsylvania: NK: Nielsen-Kellerman. http:// www.nkhome.com/kestrel-products/instruments/kestrel-4000-wea ther-environmental-meter-in-orange. (accessed 15 February 2016).

Prieto, L., Lamarca, R., \& Casado, A. (1998). La evaluación de la fiabilidad en las observaciones clínicas: El coeficiente de correlación intraclase. Medicina Clínica, 110(4), 142-145.

R Core Team. (2016). R: A language and environment for statistical computing. Vienna, Austria: R Foundation for Statistical Computing. Retrieved from https://www.R-project.org/.

Reséndiz, F. G., Gómez, V. J., \& Orea, S. M. (2004). Oximetría de pulso en el diagnóstico de asma en el niño. Revista Alergia Mexico, 51, 102-106.

Rodríguez, J. A., Garrido, H., Martínez, A., \& García, M. A.. (2013). Exactitud y Errores de la Oximetría de Pulso. in V Latin American Congress on Biomedical Engineering CLAIB 2011 May 16-21, 2011. Habana, Cuba (pp. 758-761). Berlin Heidelberg: Springer http://doi.org/ 10.1007/978-3-642-21198-0_193.

Rojas-Pérez, E. M. (2006). Factores que afectan la oximetría de pulso. Revista mexicana de anestesiología, 29, S193-S198.

Salas, H. M., \& Suárez, S. M. M. (2012). Educación médica continua: Oximetría de pulso. Revista de la Sociedad Boliviana de Pediatría, 51(2), 149-154.

Sola, A., Chow, L., \& Rogido, M.. (2005). Pulse oximetry in neonatal care in 2005. A comprehensive state of the art review. Anales de Pediatría, 62(3), 266-281. http://doi.org/10.1157/13071843

Tyco Healthcare (2006). Service Manual for N5600 Patient Monitor. USA:Tyco Healthcare.

How to cite this article: Díaz-González CDLM, de la RosaHormiga M, Ramal-López JM, González-Henríquez JJ, Marrero-Morales MS. Factors which influence concordance among measurements obtained by different pulse oximeters currently used in some clinical situations. J Clin Nurs. 2018;27:677-683. https://doi.org/10.1111/jocn.14012 